\title{
RESEARCH
}

\section{The Canadian contribution to the US physician workforce}

\author{
Robert L. Phillips Jr, Stephen Petterson, George E. Fryer Jr, Walter Rosser
}

\section{ABstraCT}

Background: A physician shortage has been declared in both Canada and the United States. We sought to examine the migration pattern of Canadian-trained physicians to the United States, the contribution of this migration to the Canadian physician shortage and policy options in light of competing shortages in both countries.

Methods: We performed a cross-sectional analysis of the 2004 and 2006 American Medical Association Physician Masterfiles, the 2002 Area Resource File and data from the Canadian Institute for Health Information, the Canadian Medical Association and the Association of Faculties of Medicine of Canada. We describe the migration pattern of Canadian medical school graduates to the United States, the number of Canadian-trained physicians in the United States in 2006, the proportion who were in active practice, the proportion who were practising in rural or underserved areas and the annual contribution of Canadian-trained physicians to the US physician workforce.

Results: Two-thirds of the 12040 Canadian-educated physicians living in the United States in 2006 were practising in direct patient care, 1023 in rural areas. About 186 , or 1 in 9 , Canadian-educated physicians from each graduating class joined the US physician workforce providing direct patient care. Canadian-educated physicians are more likely than US-educated physicians to practise in rural areas.

Interpretation: Minimizing emigration, and perhaps recruiting physicians to return to Canada, could reduce physician shortages, particularly in subspecialties and rural areas. In light of competing physician shortages, it will be important to consider policy options that reduce emigration, improve access to care and reduce reliance on physicians from developing countries.

CMAJ 2007;176(8):1083-7 ince I999, growth of the Canadian physician workforce has kept pace with population growth, in large part due to an increase in the number of family physicians (94 per 100000 in 1999 to 98 per 100000 in 2004). In contrast, the number of specialists declined from 93 per I00 000 in I999 to 9I per 100000 in $2004 .{ }^{1}$ The growth of the family physician workforce was aided by an II.9\% increase in the number of international medical graduates practising in Canada and by a $5.1 \%$ increase in graduates from Canadian medical schools between 2000 and 2004. ${ }^{1}$ Unlike people in the United States, nearly all Canadians ( $97 \%$ ) have a family physician; however, nearly I in 3 Canadians surveyed in 2002 reported difficulty finding a regular family physician or seeing their family physician when needed. ${ }^{2}$ Over half of Canadians surveyed in 2002 said it was "very" or "somewhat" difficult to see a specialist: ${ }^{2}$ Access problems are worse for rural Canadians. ${ }^{3}$

By the early ig8os, concern about medical care costs led Canada's provincial and federal governments to regard physicians as independent cost centres. This perception and a report in I99I stating that there was a physician surplus led to physician-workforce reduction policies. ${ }^{4,5}$ These policies restricted the entry of international medical graduates into Canada and reduced the size of classes in Canadian medical schools by $13.4 \%$ between I99I and $2000 .^{6}$ A series of new policies in the late I 980 and early I990s controlled health care spending, discontinued rotating internships (increasing training time and specialty training), limited interprovincial migration of new physicians and financially penalized, or threatened to penalize, new physicians practising in "overserviced" areas. ${ }^{6}$ The early I9gos also saw a wave of retirement by doctors who came to Canada in the I950s and I96os and a deliberate increase in the ratio of specialist to family medicine training positions. ${ }^{6}$ All of these factors are blamed for a relative shortage of physicians in Canada in nearly all specialties.

Changes in the emigration patterns of Canadian-educated physicians are not believed to have had a profound effect on workforce reduction; however, this view usually compares yearly emigration with the total physician workforce. ${ }^{6,7} \mathrm{Be}$ tween I98I and 2004, Canada had an annual net loss of Canadian-educated physicians, in large part due to immigration to the United States. ${ }^{1,4}$ The Association of American Medical Colleges recently pronounced an impending physician shortage in the United States and called for a 30\% expansion in medical school enrolment over the next decade and similar expansion in residency training programs. ${ }^{8}$ Given the porous nature of the Canada-US border for physician migration and pronouncements by both countries of a physician-workforce shortage, we chose to study the effects of migration on the Canadian and US physician workforces. Our objective was to examine and quantify the migration of Canadian-educated 
physicians to the United States, particularly those who chose to remain in the United States, in relation to their school of training, specialty, rural status and practice type.

\section{Methods}

We performed a cross-sectional secondary analysis of the 2006 American Medical Association (AMA) Physician Masterfile to identify and locate all graduates of Canadian medical schools who had immigrated to and were working in the United States. ${ }^{9}$ The AMA Physician Masterfile includes data on all physicians who reside in the United States, including AMA members and nonmembers and graduates of foreign medical schools. The AMA Physician Masterfile data includes physician name, medical school and year of graduation, sex, place and date of birth, geographic location and address, type of practice, present employment and practice specialty. ${ }^{10}$ We obtained data about the Canadian physician workforce from the Canadian Medical Association Physician Masterfile (2003) and the Scott's Medical Database (2005; reported by the Canadian Institute for Health Information). Summary data about the number of graduates from Canadian medical schools and their residencies were obtained from the Association of Faculties of Medicine of Canada and the Canadian Post-MD Education Registry (2005); Canadian medical school and residency graduation volumes were averaged over the most recent available decade (1996-2005). ${ }^{11,12}$ Summary data from the Scott's Medical Database about practising physicians who annually emigrate from and return to Canada were available from the Canadian Institute for Health Information. ${ }^{13,14}$ The number of physicians emigrating from and returning to Canada were averaged from 1995 through 2004 (physicians in residency training were excluded from these data in 1995 so that only physicians eligible to practise were included). Data on the number of graduates who specifically immigrated to and emigrated from the United States were received from the Canadian Institute for Health Information. Data on the number of graduates of US medical schools practising in Canada were available for 2004 from the Canadian Institute for Health Information. ${ }^{1}$

To determine the number of Canadian-educated physicians who were practising in rural or Health Professional Shortage Areas in the United States, we matched county of practice with the 2004 Area Resource File and the 2003 Rural-Urban Continuum Codes from the United States Department of Agriculture. ${ }^{15}$ To assess the degree of data lag in the AMA Physician Masterfile, we examined the longitudinal migration patterns in the 2004 and 2006 AMA Physician Masterfiles. We limited the assessment of net annual migration patterns to physicians who graduated medical school before or during 2000 to avoid counting graduates who were still in residency training in 2006. We performed all other assessments using data on physicians who graduated before or during 2006. We performed simple frequency analysis by birth country, Canadian medical school of graduation, rural versus nonrural address and whole- or partialcounty Health Professional Shortage Area status. We performed $\chi^{2}$ analysis to test for significant differences between US- and Canadian-educated physician practice locations. The number of graduates of Canadian medical schools who practised in direct patient care in the United States by graduation year was obtained from both the 2004 and 2006 AMA Physician Masterfiles and was compared with Canadian physician migration data. To quantify longitudinal effects, patterns were averaged between I960 and 2000 to account for possible attrition due to retirement (lower bound) and for graduates who might still be in residency training (upper bound).

Despite delays in data reporting and other inaccuracies such as confusion about work versus practice address, the AMA Physician Masterfile is the most complete and authoritative source of information on physicians in the United States, particularly at a national level of analysis. ${ }^{16,17}$ Previous studies that have compared AMA Physician Masterfile data with physician census surveys have found that AMA Physician Masterfile data were reliable and adequate for work-force projections and policy studies when aggregated to the state level. ${ }^{17}$ We have previously shown that the AMA Physician Masterfile is valid for rural and whole-county Health Professional Shortage Areas where the accuracy of the data is nearly $90 \%$ for county-of-practice classification. ${ }^{18}$ Canadian physician databases suffer from many of the same lags and accuracy problems as the AMA Physician Masterfile for similar reasons, particularly the administrative sources. US and Canadian databases were not directly linked but contemporary databases were used for temporal comparisons and to fill in gaps in each about the physicians who train in Canada and migrate to or from the United States.

\section{Results}

In 2006, there were 32 24I family physicians and general practice physicians and 30656 medical and surgical specialists in Canada. ${ }^{19}$ On average each year since 1996, I 642 physicians have graduated from medical school and 1683 physicians have graduated from residency training programs in Canada. ${ }^{11,12}$ Each year from 1995 to 2004, an average of 517 physicians who completed residency training in Canada left the country and 273 returned from abroad (Fig. I). For the first time in 2004, the number of physicians who returned from abroad was higher than the number that left the coun-

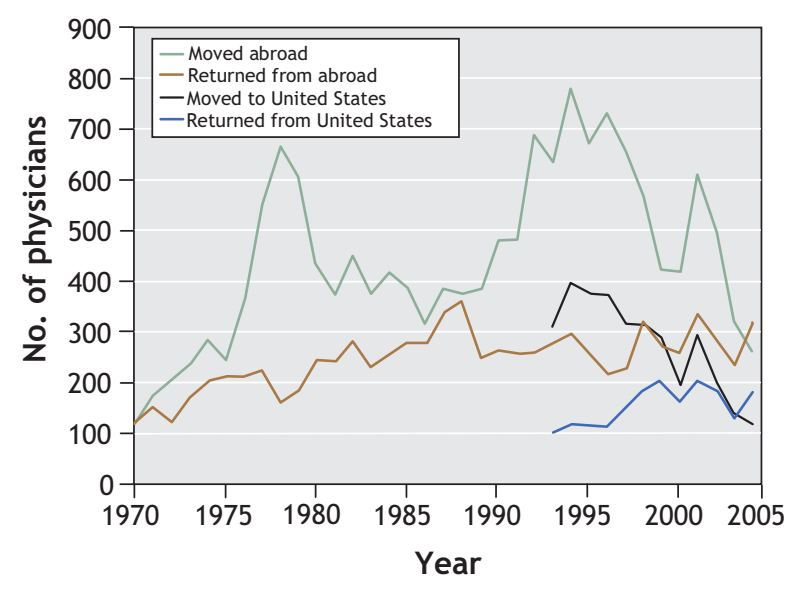

Fig. 1: Migration pattern of Canadian-educated physicians, $1970-2004^{13,14,20}$ 
try: ${ }^{1} 262$ physicians who completed their residency training in Canada left the country and 317 returned. We found that Canada contributed about 186 active, direct-patient care physicians to the US health care system annually (range 37-268); however, we found a lag of 5 or more years in our ability to monitor this from the US data. Americans who graduated from Canadian medical schools accounted for I $4.2 \%$ ( II $6 \mathrm{I} / 8 \mathrm{I} 53)$ of these physicians. Nearly half $(47.8 \%$ [576I/I2 040]) of the Canadian-educated physicians in the United States graduated from 3 Canadian medical schools: McGill University, the University of Toronto and the University of Manitoba (Table I). The 2006 AMA Physician Masterfile identified I9 2Io Canadian medical school graduates who undertook postgraduate training or practised in the United States. Of these physicians, I2 $040(62.7 \%)$ had primary addresses within the United States (Table I). Table 2 shows the major activity of Canadian-educated physicians who were practising in the United States: $8 \mathrm{I} 62$ were providing primarily direct patient care.

Of physicians providing direct patient care in the United States in $2006,69.5 \%(567 \mathrm{I} / 8 \mathrm{I} 62)$ were specialists and $30.5 \%$ (249I/8I62) were primary care physicians (Table 3), as compared with $48 \%$ and $52 \%$ respectively in the Canadian physician workforce. Canadian-educated specialists who practised in direct patient care in the United States in 2006 represented nearly one-fifth (I9.3\%) of the Canadian specialist workforce and Canadian-educated primary care physicians who provided direct patient care represented $8.0 \%$ of the Canadian primary care workforce. In contrast, there were 408 graduates of US medical schools who practised as fee-for-service physicians in Canada in $2004 .{ }^{21}$ Canadian-educated physi- cians in direct patient care were more likely than US graduates to practise in rural areas (I2.6\% v. I0.I\% [I023/8I54 V. 50 o80/495 056] $p<0.001$ ). Although Canadian-educated physicians were more likely than US-educated physicians to practise in a county that is in part designated as a Health Professional Shortage Area (72.3\% v. 67.0\% [5894/8I54 v. $332546 / 495$ 056] $p<0.001$ ), they were not more likely to practise in a whole-county Health Professional Shortage Area (I0.7\% V. II.2\% [875/8I54 V. 55 23I/495 056] $p<0.00 I$ ).

\section{Interpretation}

In 2006, I in 9 Canadian-educated physicians practised in the United States. If physicians who were born in the United States are excluded, this number is reduced to $\mathrm{I}$ in $\mathrm{I} 2$. This accounts for just over half of the net loss of physicians from the Canadian-trained physician workforce. Collectively, this is equivalent to having 2 average-sized Canadian medical schools dedicated to producing physicians for the United States. Canada is the second largest source of immigrant physicians to the United States, second only to India.

The number of emigrant physicians approximates the current physician shortage in all Canadian provinces. In addition, graduates of Canadian medical schools who practise in the United States are more likely to choose to practise in a rural area compared to US graduates. If these physicians were to choose to stay and practise in rural Canada, this would dramatically alleviate physician shortages in rural areas of the country. ${ }^{22}$ The migration of US-trained physicians to work in Canada, only 400-500 physicians, is miniscule in comparison; this was substantiated by another recent study

Table 1: Location of graduates of Canadian medical schools in 2006, stratified by medical school

\begin{tabular}{|c|c|c|c|c|}
\hline Medical school & $\begin{array}{l}\text { No. }(\%) \text { of graduates } \\
\text { in the United States } \\
\qquad n=12040\end{array}$ & $\begin{array}{c}\text { No. }(\%) \text { of graduates } \\
\text { previously in the } \\
\text { United States } \\
n=7170\end{array}$ & $\begin{array}{l}\text { No. (\%) of graduates ever } \\
\text { in the United States }{ }^{*, 9,12} \\
\qquad n=19210\end{array}$ & $\begin{array}{l}\text { Graduating class } \\
\text { size }^{12}(\%) \\
n=1765\end{array}$ \\
\hline McGill University & $2969(24.7)$ & $964(13.4)$ & $3933(20.5)$ & $116(6.6)$ \\
\hline University of Toronto & $1834(15.2)$ & $1305(18.2)$ & $3139(16.3)$ & $333(18.9)$ \\
\hline University of Manitoba & $958(8.0)$ & $531(7.4)$ & $1489(7.8)$ & $76(4.3)$ \\
\hline University of Western Ontario & $777(6.5)$ & $500(7.0)$ & $1277(6.7)$ & $100(5.7)$ \\
\hline Dalhousie University & $744(6.2)$ & $398(5.6)$ & $1142(5.9)$ & $76(4.3)$ \\
\hline University of Ottawa & $647(5.4)$ & $370(5.2)$ & $1017(5.3)$ & $109(6.2)$ \\
\hline Queen's University & $561(4.7)$ & $371(5.2)$ & $932(4.9)$ & $62(3.5)$ \\
\hline University of British Columbia & $530(4.4)$ & $443(6.2)$ & $973(5.1)$ & $159(9.0)$ \\
\hline McMaster University & $365(3.1)$ & $224(3.1)$ & $589(3.0)$ & $96(5.4)$ \\
\hline University of Calgary & $356(3.0)$ & $161(2.2)$ & $517(2.7)$ & $83(4.7)$ \\
\hline Memorial University & $279(2.3)$ & $134(1.9)$ & $413(2.2)$ & $42(2.4)$ \\
\hline University of Sherbrooke & $106(2.1)$ & $150(2.1)$ & $256(1.3)$ & $87(4.9)$ \\
\hline
\end{tabular}

*May not sum to $100 \%$ due to rounding. 
using similar data sources. ${ }^{23}$ Immigration of Canadiantrained physicians to the United States may be slowing, as there was a net gain in the number of physicians who returned to Canada in 2004.

Our findings are in contrast to pronouncements that emigration is not a major contributor to physician shortages in Canada. ${ }^{6,7}$ The annual net migration of Canadian-educated physicians has been sustained until recently. Although this migration has been well documented, its aggregate contribution to the physician shortage in Canada has not been. ${ }^{1,4}$ There may be many reasons that Canadian-educated physicians immigrate to the United States, and exploring these reasons will be an important step in designing policies that support the decision to stay in, or to return to, Canada. In the I99os, there were Canada-wide and municipal policies associated with peak emigration, such as geographic and billing restrictions, but it remains unclear how these policies affected emigration trends. ${ }^{24}$ Highly specialized physicians may have a greater opportunity to develop their skills and the earning potential can also be much greater for some specialties in the United States compared with Canada. Lower taxes in the United States and rapidly rising educational debts for Canadian-educated physicians may also increase their desire to immigrate to the United States. Canadian-educated physicians may also be responding to a rigidly controlled residency training system. Whatever the reasons for physician emigration, a lack of awareness, or a lack of response, has contributed to Canada's physician shortage. In response to physician shortages in Canada, the number of spaces in publicly-funded medical schools have been increased by $15 \%$ to $30 \%$, the first new medical school in more than 30 years has been opened, ${ }^{25}$ satellite campuses of existing medical schools have been created, ${ }^{26,27}$ the number of post-graduate positions has been increased and restrictions on international medical graduates have been loosened. ${ }^{28-30}$

There are inherent limitations of the AMA Physician Masterfile and in the cross-sectional design of our study. Because of these limitations, there is a risk of over-counting Canadian medical school graduates who train or practise in the United States and then return to Canada and a risk of undercounting physicians who have finished residency training but who are not yet counted in the physician workforce. Both

Table 2: Major activity of Canadian-educated physicians in the United States in 2006

\begin{tabular}{lcc}
\hline Activity & $\begin{array}{r}\text { No. }(\%) \text { of physicians } \\
n=12\end{array}$ \\
\hline Direct patient care & $8162(67.8)$ \\
\hline Retired or inactive & $1894(15.7)$ \\
\hline No classification & 841 & $(7.0)$ \\
\hline Resident in training & 361 & $(3.0)$ \\
\hline Medical research & 318 & $(2.6)$ \\
\hline Administration & 250 & $(2.1)$ \\
\hline Medical teaching & 140 & $(1.2)$ \\
\hline Nonpatient care & 74 & $(0.6)$ \\
\hline
\end{tabular}

the Canadian and US physician data have similar limitations in measuring migration patterns, especially for nonrespondents and in the years closest to graduation from residency training. Reliability appears to be poorest for physician data in the United States and Canada in the 3-5 years immediately after completion of residency training. Our comparisons of 2004 and 2006 AMA Physician Masterfile data suggest that this data lag may underestimate the number of Canadiantrained physicians practising in the United States by I0\% or more. It also prevents a clear picture of how migration has changed for three or more years. There is also evidence of some lag time in accounting for physicians who have migrated. We believe that the evidence points to an underestimation of migration to the United States with a lag time of 5 or more years.

Our findings suggest that physician migration to the United States may be decreasing, but that efforts to further stem this loss would be beneficial. Understanding which policies would be most potent in this regard may require further study; however past research has suggested that reducing debt loads and salary differentials between Canada and the United States, using incentives to encourage physicians to practise in specific locations or providing liberal training options may help to alleviate shortages. ${ }^{31}$ Provincial governments could consider incentives to attract Canadian-educated physicians back to Canada. Encouraging migration offers some degree of control over the physician-specialty mix and policy options to stem migration risks loosening these controls. Given the cumulative loss and physicians shortages in Canada, relaxing controls on migration may be timely. Canada also benefits from the US post-graduate training system but this benefit carries risk. Of the nearly 500 graduates of Canadian medical schools who are in US residency training programs in any given year, more than two-thirds will leave the United States and presumably return to Canada. Many physicians take advantage of training in the United States that is unavailable in Canada and do so at a cost of as much as US $\$ 48000$ ooo to the US Medicare program per year (the median Medicare payment per resident was US \$I2I I69 in

Table 3: Canadian-educated physicians in the United States in 2006, stratified by specialty

\begin{tabular}{|lcc}
\hline Specialty & $\begin{array}{c}\text { No. (\%) of } \\
\text { physicians } \\
n=12040\end{array}$ & $\begin{array}{c}\text { No. (\%) of physicians } \\
\text { in direct patient care } \\
n=8162\end{array}$ \\
\hline $\begin{array}{l}\text { Primary care } \\
\text { General/family } \\
\text { practice }\end{array}$ & $2136(17.7)$ & $1730(21.1)$ \\
\hline $\begin{array}{l}\text { General internal } \\
\text { medicine* }\end{array}$ & $810 \quad(6.7)$ & $494 \quad(6.1)$ \\
\hline $\begin{array}{l}\text { General } \\
\text { pediatrics* }\end{array}$ & $417 \quad(3.5)$ & $267 \quad(3.3)$ \\
\hline $\begin{array}{c}\text { Specialist } \\
\text { Obstetrics } \dagger\end{array}$ & $8233(68.4)$ & $5365(65.7)$ \\
\hline
\end{tabular}

*Primary care specialties in the United States tIncluded in specialist total 
200I). This training exchange benefits Canada's physician workforce, both offering and financing broader training opportunities for physicians. However, Canadian-educated physicians who complete their residency training in the United States are less likely to return to Canada and are as much as 9 times more likely than Canadian-educated physicians who completed their residency training in Canada to later immigrate to the United States. ${ }^{31}$ It may be desirable to respect this risk and permit the exchange, but to create incentives for returning to Canada.

The United States is a major beneficiary of the Canadian medical education system, and Canada is a beneficiary of US post-graduate training programs. These trade-offs may represent a mutually beneficial exchange that is not typical of most physician-donor nations. Canada and other developed countries could promote these beneficial exchanges while avoiding the "pillage" of physicians from developing countries. ${ }^{31}$

\section{This article has been peer reviewed.}

From The Robert Graham Center: Policy Studies in Family Medicine and Primary Care (Phillips, Petterson), Washington, DC; the Department of Pediatrics (Fryer), New York University, New York City, NY; and the Department of Family Medicine (Rosser), Queen's University, Kingston, Ont.

\section{Competing interests: None declared.}

Contributors: All of the authors have contributed to data collection and analysis, drafting and revising the article for important intellectual content and gave approval of the final version.

Acknowledgements: We wish to thank Lisa Klein for her considerable help with manuscript preparation, Jessica McCann for preliminary analyses and Dr. Larry Green for reviewing and helping to refine the manuscript.

Our study was based in part on data and information provided by the Canadian Institute for Health Inforamtion (CIHI). The analyses, conclusions, opinions and statements expressed herein are ours and not necessarily those of CIHI."

This study was supported by The Robert Graham Center: Policy Studies in Family Medicine and Primary Care. The information and opinions contained in research from The Graham Center do not necessarily reflect the views or the policy of The American Academy of Family Physicians.

\section{REFERENCES}

I. Canadian Institute for Health Information. Supply, distribution and migration of Canadian physicians, 2004. Ottawa: Canadian Institute for Health Information 2005. Available: http://secure.cihi.ca/cihiweb/products/SupDistandMigCanPhysic _2004_e.pdf (accessed 2007 Feb 6).

2. Canadian Medical Association. National report card 2002: summary report. Ottawa: Canadian Medical Association; 2002. Available: www.cma.ca/index.cfm /ci_id/945I/la_id/I.htm (accessed 2007 Feb 6).

3. Commission on the Future of Health Care in Canada. Rural and remote communities. In: Romanow RJ, editor. Building on values: The future of health care in Canada. Saskatoon (SK): Commission on the Future of Health Care in Canada; 2002. pi59-69. Available: www.hc-sc.gc.ca/english/pdf/romanow/pdfs/HCC_Final Report.pdf(accessed 2007 Feb 6).

4. Canadian Labour and Business Centre. Physician workforce in Canada: literature review and gap analysis. Ottawa: Canadian Labour and Business Centre; 2003 Available: www.physicianhr.ca/reports/literatureReviewGapAnalysis-e.pdf (accessed 2007 Feb 6).

5. Barer ML, Stoddart GL. Toward integrated medical resource policies for Canada. Report prepared for Federal/Provincial/Territorial Conference of Deputy Ministers of Health. I99I.

6. Chan B. From perceived surplus to perceived shortage: What happened to Canada's physician workforce in the Iggo's? Ottawa: Canadian Institute for Health Information; 2002.
7. Canadian Health Services Research Foundation. Mythbusters: Canadian doctors are leaving for the United States in droves. Ottawa: Canadian Health Services Research Foundation; 2005. Available: www.chsrf.ca/mythbusters/pdf/mythig_e.pdf (accessed 2007 Feb 6).

8. Association of American Medical Colleges. AAMC statement on the physician workforce. Washington: Association of American Medical Colleges; 2006. Available: www.aamc.org/workforce/workforceposition.pdf (accessed 2007 Feb 6).

9. American Medical Association. AMA physician masterfile. Chicago: American Medical Association; 2006.

Io. American Medical Association. AMA physician masterfile [data resources]. Available: www.ama-assn.org/ama/pub/category/2673.html (accessed 2007 Mar I4).

II. Association of Faculties of Medicine of Canada. Number of MDS awarded by Canadian Universities by Sex, I968-2006. Available: www.cma.ca/multimedia/CMA/ Content_Images/Inside_cma/Statistics/25-MD_awarded_by_sex.pdf (accessed 2007 Mar 14).

I2. Canadian Post-MD Education Registry (CAPER). Annual census of Post-MD trainees, 2005-2006. Ottawa: The Association of Faculties of Medicine of Canada; 2005. Available: www.caper.ca/docs/pdf_2005-06_CAPER_Census.pdf (accessed 2007 Feb 23).

13. Barer ML, Webber WA. Immigration and emigration of physicians to/from Canada. Health Human Resources Unit paper 99:6. Vancouver: Centre for Health Services and Policy Research, University of British Columbia; I999. Available: www.chspr.ubc.ca/files/publications/I999/hhrug9-o6.pdf (accessed 2007 Feb 6).

I4. Canadian Institute for Health Information. Supply, distribution and migration of Canadian physicians, 2000-2004. Ottawa, Canadian Institute for Health Information; 2004.

I5. Area Resource File. Rockville, MD, Health Resources and Services Administration, US Department of Health and Human Services; 2003. Available: www.arfsys.com/ (accessed 2007 Mar I4).

I6. Kletke PR. Physician workforce data: When the best is not good enough. Health Serv Res 2004;39:125I-6.

I7. Williams PT, Whitcomb M, Kessler J. Quality of the family physician component of the AMA Masterfile. J Am Board Fam Pract 1996;9:94-9.

I8. Fink K, Phillips RL, Fryer GE. Physician shortages. Health Affairs 2003;22:260-2.

19. Canadian Medical Association. Canadian Medical Association Masterfile: Number of physicians by province/territory and specialty, Canada, 2006. Available: www.cma.ca/multimedia/CMA/Content_Images/Inside_cma/Statistics/historical /specialty-prov2006.pdf (accessed 2007 Mar I4).

20. Canadian Institute for Health Information. Physicians moving abroad and returning from abroad, by province/territory, Canada, 2000-2004. Ottawa: Canadian Institute for Health Information; 2006.

2I. Canadian Institute for Health Information. Full-time equivalent physicians report Canada, 2002-2003 and 2003-2004. Ottawa: Canadian Institute for Health Information; 2006.

22. Mullan F. The metrics of the physician brain drain. N Engl JMed 2005;353:1810-8.

23. Rourke J, Dewar D, Harris K, et al. Task Force of the Society of Rural Physicians of Canada. Strategies to increase the enrolment of students of rural origin in medical school: Recommendations from the Society of Rural Physicians of Canada. CMA 2005;172:62-5.

24. Bourgeault IL. On the move: A comparative examination of the migration of physicians and nurses into and out of Canada, the US, the UK and Australia [presentation]. Canadian Economics Association Conference on Health Human Resources; 2005 May 27-8; Hamilton (ON).

25. Ministry of Northern Development and Mines. Harris government announces new northern medical school and increased medical school enrolment [news release]. Sault Ste. Marie (ON): Ministry of Northern Development and Mines; 200 I May 17. Available: www.mndm.gov.on.ca/MNDM/pub/newrel/NRView.asp?NRNUM $=46 \&$ NRYear $=2001 \& N R L A N=E N \& N R I D=690($ accessed 2007 Feb 6$)$.

26. Ontario Ministry of Training, Colleges and Universities. McGuinty government creates ro4 new spaces for medical raining [news release]. Toronto: Ontario Ministry of Training, Colleges, and Universities; 2006 Feb 9. Available: http://ogov.newswire.ca lontario/GPOE/2006/02/09/c0773.html? Imatch-\&lag=e.html (accessed 2007 Feb 6).

27. Snadden D, Bates J. Exapnding undergraduate medical education in British Columbia: A distributed campus model. CMAJ 2005;173:589-90.

28. College of Family Physicians of Canada. Shaping the future of health care: Submission to the Commission on the Future of Health in Canada. Mississauga (ON): College of Family Physicians of Canada; 200I.

29. Stevens D. In Canada, desperately seeking doctors. AAMC Reporter 2000;9.

3o. Health Canada. Federal funding enables more foreign-trained doctors to work in Canada [news release]. Ottawa: Health Canada; 2004 Mar I. Available: www.hc-sc .gc.ca/ahc-asc/media/nr-cp/2004/2004_08_e.html (accessed 2007 Feb 6).

31. McKendry RJR, Wells GA, Dale P, et al. Factors influencing the emgiration of physicians from Canada to the United States. $C M A J$ I996;154:I7I-8I.

Correspondence to: Dr. Robert L. Phillips Jr, The Robert Graham Center: Policy Studies in Family Medicine and Primary Care, Suite 20I, I350 Connecticut Ave. NW, Washington DC 20036; fax 202 986-7034; bphillips@aafp.org 